\title{
Analysis of the treatment costs of HIV/AIDS in Turkey
}

\author{
Guvenc Kockaya ${ }^{1}$, Tuba Elbir Zengin ${ }^{1}$, Fatma Betul Yenilmez ${ }^{2}$, Canan Dalgic ${ }^{1}$, \\ Simten Malhan ${ }^{3}$, Pamir Cerci ${ }^{2}$, Ergun Oksuz $^{3}$, Serhat Unal ${ }^{2}$ \\ Gilead Sciences Turkey, Istanbul, Turkey \\ Hacettepe University, Ankara, Turkey \\ Baskent University, Ankara, Turkey
}

\begin{abstract}
OBJECTIVE: Infection with the human immunodeficiency virus (HIV), the causative agent of acquired immune deficiency syndrome (AIDS), is a major global health problem. Patients with HIV can live normal lives with today's new treatment options. As the treatment is generally successful, the life expectancy of patients infected with HIV is rising. As a result, the economic burden of HIV treatment on health systems is set to increase. According to the Ministry of Health, there were more than 6000 HIV-positive patients in Turkey in 2013. The aim of this study was to determine the direct costs of HIV treatment in Turkey.

METHOD: A retrospective data analysis was performed from the reimbursement agency perspective. Data for 252 patients at a university hospital in Ankara from 2001 to 2012 were used for the analysis. The average costs of treatment per HIV patient and the average costs per HIV patient, depending on the state of the patient's health, were calculated. The latter was determined according to the number of CD4 cells $/ \mathrm{ml}$, as defined by the CDC's classification system for HIV infection. The cost of treatment was calculated based on published reimbursement prices in 2013, per patient per year.

RESULTS: The CD4 values of $25.3 \%, 29 \%$, and $45.7 \%$ of the 252 patients were $<100$ cells $/ \mathrm{mm} 3,100-300$ cells $/ \mathrm{mm} 3$, and $>300$ cells $/ \mathrm{mm} 3$, respectively. The treatment costs per patient per year for 2013 for those with CD4 values of $<100$ cells/ $\mathrm{mm} 3,100-300$ cells $/ \mathrm{mm} 3$, and $>300+$ cells $/ \mathrm{mm} 3$ were $\$ 5,637.04, \$ 2,211.54$, and $\$ 2,182.35$, respectively. The weighted average of the treatment cost per patient was $\$ 3,344.64$ for 2013 .

CONCLUSION: This analysis is unique to Turkey and calculates the cost only of HIV treatment in Turkey. Lower CD4 values are associated with higher treatment costs. Appropriate HIV treatment is crucial for controlling CD4 values and lowering the treatment costs of HIV patients. These findings need to be considered by policy makers who may need to focus on HIV.
\end{abstract}

\section{Keywords}

HIV/AIDS; Cost of treatment; Turkey

\section{INTRODUCTION}

According to a 2014 report by the World Health Organization (WHO), 35 million people are infected worldwide with the human immunodeficiency virus (HIV) [1]. In 2013, 2.1 million people were newly infected, with the number of deaths related to acquired immune deficiency syndrome (AIDS) about 1.5 million [1]. In Turkey, according to Ministry of Health data published in 2013, more than 6000 people were infected with HIV [2]. The numbers of new cases in 2010, 2010, and 2013 (the first 6 months) in the same report were $589,1,068$, and 587, respectively [2]. HIV transmission includes heterosexual intercourse, homosexual/bisexual intercourse, intravenous drug use, nosocomial transmission, vertical transmission, and unknown reasons [3]. The HIV-1 RNA concentration (viral load) is an important predictor of the HIV transmission level through sexual intercourse, needle sharing, or from mother to infant [3]. The CD4 cell count is the most important predictor of patient survival when starting antiretroviral (ART) HIV therapy. In patients with lower CD4 cell counts, the immune deficiency may be irreversible and early treatment shows more benefits when compared to delayed treatment [4].

In 2009, the WHO recommended new regimens for ART treatments and recommended ART treatment for adults and adolescents with early stage disease $[5,6]$. These revised ART treatment guidelines also recommended ART treatment for all adults and adolescents, including HIV-infected pregnant women,
Corresponding author Guvenc Kockaya guvenc.kockaya@gilead.com

\section{Disclosure}

This study was supported by Gilead Science Turkey 
with a CD4 count of $<350$ cells $/ \mathrm{mm}^{3}$, regardless of clinical symptoms [5]. While the WHO's 2009 guidelines were outdated, the newly published guidelines recommend treatment as soon as possible [6].

According to data from a cost-effectiveness study in sub-Saharan Africa, HIV prevention was 28 times more cost-effective than highly active ART treatment (HAART) [7]. According to that study, each 1 year of life acquired by HAART equaled to 28 years of life acquired by prevention. In the metaanalysis of Creese et al. [8], there were gross differences between interventions in terms of cost-effectiveness. Furthermore aiming at condom dispensation in treatment of sexually-transmitted diseases and selective blood safety measurements led to $\$ 11$ cost for each prevented HIV patient, and 1 DALY (lost life year) was gained for each $1 \$[8]$.

Today in Turkey diagnostic methods and ART treatment are provided free of charge to HIV patients as part of a national insurance system [9]. However, no previous studies have reported the disease- and treatment-related costs of HIV in Turkey. The main goal of the present study was to determine the treatment costs of HIV patients in Turkey.

\section{MATERIALS AND METHODS}

\section{Data collection}

To obtain data for the cost analysis, patient files of a university hospital in Ankara were retrospectively evaluated. The university hospital in Ankara was one of the first HIV clinics in Turkey and is a reference center for the entire country. Within a 12-year follow-up period (2001-2012) in the university hospital, 252 patients allocated, and data included polyclinic, clinic, intervention, laboratory and imaging tests, medications, side effects, comorbidities, treatments, and complications.

\section{Classification of the patient groups}

The HIV patients were classified according to their $\mathrm{CD} 4$ cell counts $\left(\mathrm{cell} / \mathrm{mm}^{3}\right)$. Group 1 consisted of patients with CD4 cell counts of $<100$ cells $/ \mathrm{mm}^{3}$, Group 2 consisted of those

\begin{tabular}{lcc}
\hline Classification & CD4 Cell Count (cell/mm $)$ & Distribution (n. 252) \\
\hline Group 1 & $<100$ & $25.3 \%$ \\
Group 2 & $100-300$ & $29 \%$ \\
Group 3 & $>300$ & $45.7 \%$ \\
\hline
\end{tabular}

Table I. Classification of the patients according to their CD4 cell counts and their distribution with cell counts of $100-300$ cells $/ \mathrm{mm}^{3}$, and Group 3 consisted of those with cell counts of $>300$ cells $/ \mathrm{mm}^{3}$. Patient distribution of the university hospital was used as the generalization of estimation of expert opinions (Table I).

\section{Health service-related cost calculations}

In the analysis, the total cost of hospital outpatient clinics was calculated by using gynecology, infectious disease, psychiatry, neurology, dermatology, physical therapy and rehabilitation, emergency medicine, internal diseases/endocrinology visits, percent of patients in visits, number of visits per patient, and cost of visit. Cost of tests were calculated by using percent patients requiring test, number of tests per patient, and cost of each test. The cost of infection was calculated by using data on the number of hospitalizations per year, percentage of patients requiring hospitalization, mean number of days of hospitalization, daily costs of hospitalization, and total costs of hospitalization. The total costs of complications were calculated based on the percentage of patients with side effects and treatment duration of the complications. Clinical and intensive care hospitalization costs were included in the cost calculations. The clinical and intensive care hospitalization costs were calculated by using the number of annual hospitalizations, percentage of patients requiring hospitalization, mean duration of the hospital stay, and daily cost of hospitalization. The annual number of interventions, percentage of patients requiring interventions, number of interventions, and costs of interventions were used to calculate the total cost of intensive care interventions. In the cost calculation, the cost of health services was based on the 2013 prices of the Health Administration Notification of Social Security Institution. The costs obtained in Turkish lira were converted into U.S. dollars based on the mid-year exchange ratio in 2013 of $\$ 1.90$.

\section{Estimation of the cost per patient}

The disease costs were calculated for each CD4 patient group. The weighted mean method and patient distribution were used to calculate the annual cost of HIV per capita. The costs of ART drugs were excluded from the analysis.

\section{RESULTS}

The costs of the treatment in the three groups and the weighted mean cost of HIV patients are reported in Table II. The healthcare costs 


\begin{tabular}{lccccc}
\hline \multicolumn{1}{c}{ HIV classification } & $\begin{array}{c}\text { Outpatient visits } \\
\text { (\$ pro capita) }\end{array}$ & $\begin{array}{c}\text { Laboratory } \\
\text { (\$ pro capita) }\end{array}$ & $\begin{array}{c}\text { Inpatient visits } \\
\text { (\$ pro capita) }\end{array}$ & $\begin{array}{c}\text { Complications } \\
\text { (\$ pro capita) }\end{array}$ & $\begin{array}{c}\text { Total healthcare cost } \\
\text { (\$ pro capita) }\end{array}$ \\
\hline Group 1 & 192.07 & $1,297.09$ & $1,888.81$ & $2,259.05$ & $5,637.04$ \\
Group 2 & 82.00 & 760.04 & 306.72 & $1,062.78$ & $2,211.54$ \\
Group 3 & 76.57 & 773.20 & 47.36 & $1,285.20$ & $2,182.35$ \\
Weighted mean cost (\$) & & & & & $3,344.64$ \\
\hline
\end{tabular}

Table II. Total healthcare costs of HIV patients

*The costs of ART pharmaceuticals were excluded

of Group 1, 2, and 3 were \$5,637.04, \$ $2,211.54$, and $\$ 2,182.34$, respectively. When these data were used to calculate the annual HIV weighted cost per patient, the cost was \$3,344.64.

\section{DISCUSSION}

In Turkey, the treatment cost of HIV/AIDS is not evaluated in terms of the disease burden. This may be due to the lower numbers of HIV patients compared with those in developed countries. However, considering reports of increases in the numbers of new patients in Turkey [2], it may be necessary to determine the cost of HIV to understand the burden of the diseases in the country.

The cost of HIV infections in the U.S. was estimated to be $\$ 36.4$ billion (direct and indirect costs) in 2002. Of this, $\$ 6.7$ billion comprised direct treatment costs, and $\$ 29.7$ billion comprised indirect costs. According to a sensitivity analysis of the cost analysis in the United States, universal ART utilization and more effective ART regimes would reduce the disease cost [10]. In the U.S the direct and indirect costs of HIV increased from \$ 36.4 billion in 2002 to $\$ 51.2$ billion in 2009 , and HIV was among the top 20 diseases in terms of disease cost [11]. Another analysis based on Medicaid claims in the state of California reported that the medical cost per patient was $\$ 36,469$ [12].

The cost of HIV treatment per patient was estimated to be $€ 11,638, € 32,110, € 14,821$, $€ 6,399$, and $€ 25,340$ in Spain, Germany, France, Italy, and the U.K. respectively [13]. According to that report, there was great disparity in the total medical costs for patients with CD4 lymphocyte counts of 200-500 cells $/ \mathrm{mm}^{3}$ [13]. For example, in Italy the total healthcare cost of HIV treatment per patient was reported to be $€ 19,252, € 12,227$, and $€$ 6,399 for CD4 counts of $<200,>200$ but $<$ 500 , and $>500$, respectively [13].

According to a study conducted in the U.S. in 2006, adult HIV patients with a CD4 count higher than $350 / \mathrm{ml}$ who were receiving ART treatment had a predicted expected life expectancy of 24.2 years [14]. In that study, the re-

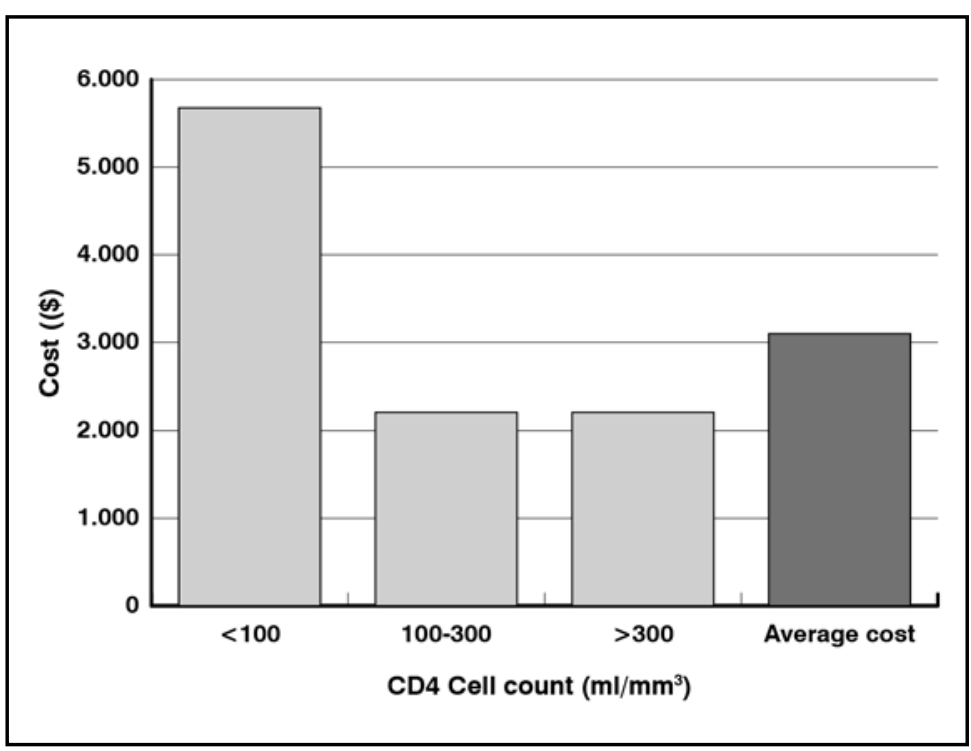

Figure 1. Annual cost (\$) per patient in the CD4 cell count classification groups

duced and unreduced life cost of these patients were $\$ 385,200$ and $\$ 618,900$, respectively. Of these costs, ART drugs accounted for $73 \%$, hospitalization accounted for $13 \%$, outpatient treatment accounted for $9 \%$, and HIV-related drugs and laboratory tests accounted for $5 \% \mathrm{~s}$. In patients with a CD4 count higher than 200/ $\mu 1$, ART treatment led to 22.5 years of expected life. The reduced and unreduced life cost of these patients were calculated to be $\$$ 354,100 and $\$ 567,000$, respectively.

According to a 2011 study conducted in 22,315 patients, starting earlier ART treatment of patients led to significantly increased survival [15]. The primary goal of ART treatment is to prevent mortality and morbidity related to chronic HIV infection. According to previous research, patients with a CD4 cell count of $<200$ cell $/ \mathrm{mm}^{3}$ had higher cumulative direct HIV treatment costs in cases of delayed treatment when compared to patients who had early treatment [16]. According to another study, decreased HIV transmission due to ART treatment might reduce the growth of the HIV epidemic and related costs [17].

The results of the analysis highlight the cost of HIV healthcare in Turkey. According to the analysis, the weighted mean healthcare cost 
of treating each HIV patient in Turkey was $\$ 3,344$.64. In addition, the treatment cost of patients with a CD4 level of $<100$ cell $/ \mathrm{mm}^{3}$ was two-fold higher than that of patients with a CD4 level of $100-300 \mathrm{cell} / \mathrm{mm}^{3}$ or $>300 \mathrm{cell} /$ $\mathrm{mm}^{3}$. These findings are similar to those reported in the international literature [10-17]. A limitation of the present study is the study sample, which consisted of patients who attended a university hospital. These might not be representative of the greater population in Turkey.

\section{CONCLUSION}

This study is the first economic analysis of HIV in Turkey. Given the continued rise in the number of new patients diagnosed with HIV/AIDS annually in Turkey, its social and economic impacts on the Turkish population need to be determined to understand the burden of the disease. Future studies should include a greater number of hospitals and centers to reflect the national context.

The present analysis demonstrated that the cost of treatment rose in accordance with a decrease in CD4 levels, possibly pointing to a direct relationship between CD4 levels and treatment costs. Start treatment at an early stage prior to a fall in CD4 cell counts may reduce healthcare costs. These findings may be useful to clinicians treating HIV patients and decision makers charged with shaping future of HIV/AIDS health care policies.

\section{REFERENCES}

1. World Health Organization. Fast Track Ending The AIDS Epidemic by 2030. Available at: http://www.unaids.org/ sites/default/files/media_asset/JC2686_WAD2014report_en.pdf (last accessed January 2015)

2. AIDS Cases and its Carriers in Turkey Distribution by years. Available at http://www.hatam.hacettepe.edu.tr/veriler_Haziran_2013.pdf (last accessed January 2015)

3. Montaner JS, Lima VD, Harrigan PR, et al. Expansion of HAART Coverage Is Associated with Sustained Decreases in HIV/AIDS Morbidity, Mortality and HIV Transmission: The "HIV Treatment as Prevention" Experience in a Canadian Setting. PLoS ONE 2014; 9: e87872; http://dx.doi.org/10.1371/journal.pone.0087872

4. Edward J, Millsa EJ, Bakandab C, et al. Mortality by baseline CD4 cell count among HIV patients initiating antiretroviral therapy: evidence from a large cohort in Uganda. AIDS 2011; 25: 851-5; http://dx.doi.org/10.1097/ QAD.0b013e32834564e9

5. World Health Organization. Towards Universal Access Scaling up priority HIV/AIDS interventions in the health sector Progress Report, 2010. Available at: https://vpn.ku.edu.tr/iris/bitstream/10665/44443/1/,DanaInfo=apps.who. int+9789241500395_eng.pdf (last accessed January 2015)

6. British HIV Association. British HIV Association guidelines for the treatment of HIV-1-positive adults with antiretroviral therapy 2012. HIV Medicine 2014; 15 (Suppl. 1): 1-85

7. Marseille E, Hofmann PB, Kahn JG. HIV prevention before HAART in sub-Saharan Africa. Lancet 2002; 359: 1851-56; http://dx.doi.org/10.1016/S0140-6736(02)08705-6

8. Creese A, Floyd K, Alban A, et al. Cost-effectiveness of HIV/AIDS interventions in Africa: a systematic review of the evidence. Lancet 2002; 359: 1635-42; http://dx.doi.org/10.1016/S0140-6736(02)08595-1

9. Erdem H ve Akova M. Leading infectious diseases problems in Turkey. Clin Microbiol Infect 2012; 18: 1056-67; http://dx.doi.org/10.1111/1469-0691.12000

10. Hutchinson AB, Farnham PG, Dean HD, et al. The Economic Burden of HIV in the United States in the Era of Highly Active Antiretroviral Therapy Evidence of Continuing Racial and Ethnic Differences. J Acquir Immune Defic Syndr 2006; 43: 451-7

11. Kockaya G, Wertheimer A. What are the top most costly diseases for USA? The alignment of burden of illness with prevention and screening expenditures. Journal of Health 2010; 2: 1174-8; http://dx.doi.org/10.4236/health.2010.210172

12. Leibowitz AA, Desmond K. Identifying a Sample of HIV-Positive Beneficiaries From Medicaid Claims Data and Estimating Their Treatment Costs. Am J Public Health 2015; 105: 567-74; http://dx.doi.org/10.2105/AJPH.2014.302263

13. Trapero-Bertran M, Oliva-Moreno J. Economic impact of HIV/AIDS: a systematic review in five European countries. Health Economics Review 2014; 4: 15; http://dx.doi.org/10.1186/s13561-014-0015-5

14. Schackman BR, Gebo KA, Walensky, RP, et al. The Lifetime Cost of Current Human Immunodeficiency Virus Care in the United States. Med Care 2006; 44: 990-7; http://dx.doi.org/10.1097/01.mlr.0000228021.89490.2a 
15. Edward J, Millsa EJ, Bakandab C, et al. Mortality by baseline CD4 cell count among HIV patients initiating antiretroviral therapy: evidence from a large cohort in Uganda. AIDS 2011; 25: 851-5; http://dx.doi.org/10.1097/ QAD.0b013e32834564e9

16. Fleishman JA, Yehia BR, Moore RD, et al.; HIV Research Network. The Economic Burden of Late Entry Into Medical Care for Patients With HIV Infection. Med Care 2010; 48): 1071-9; http://dx.doi.org/10.1097/ MLR.0b013e3181f81c4a

17. Lima VD, Johnston K, Hogg RS, et al. Expanded access to highly active antiretroviral therapy: a potentially powerful strategy to curb the growth of the HIV epidemic. J Infect Dis 2008; 198: 59-67; http://dx.doi.org/10.1086/588673 